\title{
Management of Fever Attack in a Patient with PFAPA Syndrome
}

\author{
Muhammet Mesut Nezir ENGIN*, Serdar POP
}

Sakarya University Training and Research Hospital, Department of Pediatrics

*Corresponding Author: Muhammet Mesut Nezir ENGIN, Sakarya University Training and Research Hospital, Department of Pediatrics.

Received date: March 29, 2021; Accepted date: April 23, 2021; Published date: April 26, 2021

Citation: Engin MMN. (2021) Management of Fever Attack in a Patient with PFAPA Syndrome. Clinical Research and Clinical Trials. 3(2); DOI: 10.31579/2693-4779/032

Copyright:@ 2021 Muhammet Mesut Nezir ENGIN, This is an open access article distributed under the Creative Commons Attribution License, which permits unrestricted use, distribution, and reproduction in any medium, provided the original work is properly cited.

\section{Abstract}

Fever is a common symptom in childhood and primarily suggests infectious diseases. The syndrome of periodic fever, aphthous stomatitis, pharyngitis and cervical adenitis (PFAPA syndrome) is a periodic fever syndrome of unknown incidence and is not rare in childhood. In this case report, the management of a patient who was followed up for PFAPA syndrome during a fever attack is presented.

Keywords: fever; pfapa syndrome; infectious diseases

\section{Introduction}

Fever is a common symptom in childhood and primarily suggests infectious diseases. During the infection, fever, general condition disorder, anorexia, nausea, vomiting and symptoms related to the localization of the infection may be observed. In addition to the patient's clinic, impairments are observed in laboratory values. The most common finding is an increase in acute phase reactants (AFRs) and leucocytosis in bacterial infections [1,2].

The syndrome of periodic fever, aphthous stomatitis, pharyngitis and cervical adenitis (PFAPA syndrome) is a periodic fever syndrome of unknown incidence and is not rare in childhood. The characteristic feature of the syndrome is high fever, which is seen in all patients and recurs regularly every 3-6 weeks, lasts 3-6 days, starts suddenly and can reach $41^{\circ} \mathrm{C}$. Patients are completely healthy between attacks [3].

In this case report, the management of a patient who was followed up for PFAPA syndrome during a fever attack is presented.

\section{Case Report}

A 33-month-old patient who was followed-up for PFAPA syndrome and previous febrile convulsion was admitted to the Pediatric Emergency Department with fever. Physical examination revealed fever of 39 degrees, aphthous stomatitis and pharyngitis. Other system examinations were normal. Hemoglobin: $11.1 \mathrm{mg} / \mathrm{dl}$, leukocyte: 20 thousand and Creactive protein $(\mathrm{CRP}): 80 \mathrm{mg} / \mathrm{l}$ were found in the tests. Other tests were normal. The patient was admitted to the pediatric service for follow-up. Empirical antibiotics were not started after family consent was obtained. Methylprednisolone was administered at $1 \mathrm{mg} / \mathrm{kg} I V$. The patient, who had no fever for 24 hours and whose symptoms regressed dramatically, was discharged. When he came to the polyclinic control on the fifth day of his fever, it was observed that he did not have any complaints, and his leukocyte and CRP were found to be normal in the examinations. Also, no growth was detected in throat culture.

\section{Discussion}

When fever, aphthous stomatitis, pharyngitis and adenitis are observed in the patient, the first disease that comes to mind is upper respiratory tract infections (URTI). The most common findings in the case of URTI are fever and sore throat. Increase in AFR and leukocytosis may be observed in URI. CRP, procalcitonin (PCT) and erythrocyte sedimentation rate (ESR) are generally used as AFR (4-5).

URTI is usually diagnosed clinically and treated. Immunodeficiency, adenoid hypertrophy, hypertrophic tonsils, allergic diseases and recurrent fever syndromes should be considered in the differential diagnosis when there is a history of recurrent fever or URTI. Periodic fever syndromes include PFAPA syndrome, mevolenate kinase deficiency (hyper IgD syndrome), familial mediterranean fever (FMF), cyclic neutropenia, fever syndrome with tumor necrosis factor receptor defect, cryoprinopathies, familial cold autoinflammatory syndrome, systemic form juvenile idiopathic and Crohn's disease. However, apart from these, there may be many diseases that are not yet known and can be seen with different clinical pictures [6,7].

PFAPA syndrome is the most common cause of periodic fever in childhood and was first described by Marshall et al in 1987. The onset of the disease usually begins before the age of 5 and usually resolves during adolescence. Patients are asymptomatic between episodes and show normal growth. PFAPA syndrome is an immune mediated disease characterised by a cytokine dysfunction; moreover, the strong familial clustering suggests a potential genetic origin of the syndrome. Although the clinical picture of the syndrome is well defined, the absence of a disease-specific laboratory finding makes diagnosis difficult $[3,8,9,10]$.

PFAPA syndrome responds dramatically to steroid therapy. The diagnosis is made in this way. The clinical features of PFAPA syndrome are known to mimic URTI, but there are limited evaluations in the literature about the laboratory values of patients with PFAPA syndrome during an attack. In our case, the excessive increase in leukocytosis and AFR together with fever suggested an infectious disease. However, since our patient was diagnosed with PFAPA syndrome, the current clinical and laboratory findings were thought to be due to this, and a throat culture was taken and 
empirical antibiotics were not started. The clinical findings of the patient regressed after a single dose of methylprednisolone, and the laboratory findings of the patient also improved.

\section{Conclusion}

PFAPA syndrome should be considered in the differential diagnosis in recurrent upper respiratory tract infections or patients with recurrent fever. It should be kept in mind that PFAPA syndrome will cause an increase in AFR and leukocyte values, as in our case. We believe that patients with suspected PFAPA syndrome can be followed up closely without antibiotics after taking a throat culture and performing steroid therapy. However, if there is no dramatic improvement in the patient's symptoms, if there is an increase in AFR or if a growth is detected in the throat culture, antibiotic treatment should be reconsidered.

\section{References}

1. Hatipoğlu H, Erkal S, Türkmen S, Engerek N, Kurt K, Şiraneci R. (2011) Laboratory in the Diagnosis of Infectious Diseases Findings. JOPP Journal 3(1):5-11.

2. Alıravcı İ, Akıncı E, Alkan Çeviker S. (2020) Ateş nedeniyle enfeksiyon hastalıkları kliniğine yatırılarak takip ve tedavi edilen hastaların retrospektif değerlendirilmesi.. Pam Tıp Derg. 13(2): 276-283.

3. Vanoni F, Theodoropoulou K, Hofer M. (2016) PFAPA syndrome: a review on treatment and outcome. Pediatric Rheumatology14:38.
4. Shulman ST, Bisno AL, Clegg HW, et al. (2012) Clinical practice guideline for the diagnosis and management of group A streptococcal pharyngitis: 2012 update by the Infectious Diseases Society of America. 55:86-102.

5. Hacımustafaoğlu M. (2017) Acute Phase Reactants (Erythrocyte Sedimentation Rate, CRP) J Pediatr Inf 11: 53-55.

6. Camcioğlu Y. (2010) Recurrent Respiratory Tract Infections in Relation to Immunodeficiencies and Atopy. Turkiye Klinikleri J Pediatr Sci.6 (4):83-90.

7. Ünüvar E. (2010) Periodic Fever Syndromes in Children. ANKEM Journal24(Ek 2):164-167

8. Marshall GS, Edwards KM, Butler J, Lawton AR. (1987) Syndrome of periodic fever, pharyngitis, and aphthous stomatitis. J Pediatr.110 (1):43-6.

9. Thomas KT, Feder Jr HM, Lawton AR, Edwards KM. (1999) Periodic fever syndrome in children. J Pediatr.135 (1):15-21.

10. Stojanov S, Hoffmann F, Kery A, Renner ED, Hartl D, Lohse P, Huss K, Fraunberger P, Malley JD, Zellerer S, Albert MH, Belohradsky BH. (2006) Cytokine profile in PFAPA syndrome suggests continuous inflammation and reduced anti-inflammatory response. Eur Cytokine Netw.17 (2):90-7. 